\title{
Inverse Marcus-Gunn phenomenon
}

\author{
INSERM
}

\section{Source}

INSERM. (1999). Orphanet: an online rare disease and orphan drug data base. Inverse Marcus-Gunn phenomenon. ORPHA:98951

Inverse Marcus-Gunn phenomenon is a rare congenital synkinesis where jaw opening by the pterygoid muscle (during eating or yawning) causes eyelid drooping from inhibition of the oculomotor nerve to the levator palpebrae superioris. Familial occurrence has been reported. 